analgesia and this second work is devoted to general anaesthesia. Dr. A. David Weaver has now made an excellent translation of both volumes. The subject matter of the present book is well presented and is divided into four parts with an introductory chapter on the history of anaesthesia. Part I deals with the principles of anaesthesia including tho application of physies and physiology. Part II considers drugs which may bo used in anaesthesia and Part III describes techniques and accidents and complications associated with anaes. thesia. Part IV is concerned with the application of anaesthesia to different species including, in addition to the domesticated animals, small laboratory ones, wild or captive creatures, birds, fish and frogs.

The authors have attempted a comprehensive coverage of the subject of general anaosthesia in animals, and since the volume is of moderate size it is not surprising to find that many aspects are dealt with briefly. It is perhaps unfortunate, however, that this should have beon the case with such important topics as the general prepara. tion and post-anaesthetic care of the patient. Some of the techniques, such as endotracheal intubation are poorly described, while others, notably those describing the use of barbiturates in horses, could lead to serious trouble if carried out literally. In addition, somo surprising statements are to be found, for example: "As a direct result of its unphysiological breeding, the pig is a very poor subject for goneral anaesthesia". Terminology is sometimos at variance with that generally accepted among anaesthetists, for example, no distinction is mado between vontilation and respiration and the term "forced ventilation" is used instead of "controlled ventilation".

The pharmacology of anaesthetic agents is woll described and the appendix contains a useful list of drugs. The bibliography is extensive, but seloction of a particular reference is tedious since they are listed together at the end of tho book. This book contains much useful informa. tion and is well illustrated, but the general standard of the text is variable.

Barbara M. Q. Weavter

\section{INTEGRAL EQUATIONS}

\section{Integral Equations and their Applications}

Vol. 1. By W. Pogorzelski. (International Series of Monographs in Pure and Applied Mathematics, Vol. 88.) Pp. xiii +714 . (London and New York: Pergamon Press Ltd.; Warszawa: PWN-Polish Scientific Publishers, 1966.) $120 s$.

Turs book is a translation from the Polish of three separate volumes which appeared between 1953 and 1960, and so divides naturally into three parts. The aim of the book is to present the general thoory of integral equations, together with their applications. Special techniques, such as the use of Fourier transforms, which load to explicit solutions in certain cases, are not considered.

The first part gives an account of the theory of Fredholm integral equations. The Fredholm theory for equations of the second kind and the Hilbert-Schmidt theory for symmetric kenels are given in some detail. Other topics treated here are Frodholm equations of the first kind and Volterra equations. The troatment in this part is classical, little use boing made of functional analysis. This soction could well serve as an introduction to the theory of linear intogral equations, and may be read without previous knowledge of the subjoct.

Tho second part is chiefly concorned with applications of the intogral equations studiod previously to tho theory of linear ordinary differential equations and to second order linear partial differontial oquations of all three types. The treatmont of partial differential equations is given in considerable detail with discussions of tho reduction of many of the classical boundary value problems to inte- gral equations. This part also includes a treatment of non-linear oquations by use of functional analysis and the Banach and Schauder fixed point theorems.

The third part deals mainly with strongly singular linear integral oquations, that is, equations containing an integral which convergos only as a Cauchy type limit. These oquations are then applied to several problems in potential theory. There is also a section on strongly singular non-linear equations.

As this description of the contents shows, the range of topics considered is wide. The book should be useful as a reference work with a broad coverage for applied mathematicians, physicists and engineers, and in particular to those interested in the treatment of partial differential equations by integral equations.

V. HUTSON

\section{SOVIET MAMMALS}

Mammals of the U.S.S.R. and Adjacent Countries Mammals of Eastern Europe and Northern Asia. By S. I. Ognov. Vol. 4: Rodents. Translated from the Russian by Jean Salkind. Edited by O. Thoodor. Pp. $\mathrm{x}+429+61$ tables. (Jerusalem: Israel Program for Scientific Translations; London: Oldbourne Press, 1966.) $142 s$.

'THIs volume, the fourth on rodents in the series of Mammals of the U.S.S.R. and Adjacent Countries, deals with the pikas, hares, rabbits, squirrels and chipmunks. Although basically a systematic work, it is a great deal more besidos. The disparate natures of systematic accounts and general biological works aro blended together in such a way that tho bare bones are well clothed. Details are given of morphology, taxonomy, ecology and behaviour as woll as valuable information not readily available on the role of these rodents as agricultural pests. There are accounts of the cyclic nature of hare populations and of epizootics in fluctuations. Not least is the detailed zoogeographical information which is one of the chiof contributions of this volume and of the series as a whole. Liko its predecessors, this book is a mine of information of the greatost value to the mammalogist.

The text is generally easy to read. Many of the field observations are verbatim accounts by the original observers and this makes for somo pleasant changes in style. There are many tables and these are clear and comprehonsive.

The small single page maps of other volumes have been replaced by larger detachable folding maps. Increase in size has unfortunately not been matched by increase in clarity - the shading in some cases is coarse and obscures geographical detail. The book is woll illustrated by a variety of contributors. Many of the drawings are dolightful, although a few are of more artistio than scientific value. Some of the original colour plates, now in black and white, have been so darkened that they serve little purpose and could have beon omitted without detriment. These are, however, minor mattors and do little to detract from the great valuo of the volume and the series.

G. I. TwIGG

\section{ELECTRON MICROSCOPY COMPENDIUM}

\section{Techniques for Electron Microscopy}

Edited by Desmond H. Kay. Second odition. Pp. xiv +560 . (Oxford: Blackwell Scientific Publications, 1965.) 84s. net.

MY first reaction to the second edition of this book is critical, in that metallurgists are forced to pay (handsomely) for a great deal of information on the preparation 